\title{
PENERAPAN ALGORITMA ROUGH SET DALAM MEMPREDIKSI HASIL UJIAN KOMPETENSI KEBIDANAN
}

\author{
${ }^{1}$ Arius Satoni Kurniawansyah, ${ }^{2}$ Ila Yati Beti \\ ${ }^{1,2}$ Universitas Dehasen Bengkulu, Indonesia \\ ariussatoni@unived.ac.id
}

\section{Article Info \\ Article history: \\ Received, 29-03-2021 \\ Revised, 02-06-2021 \\ Accepted, 18-06-2021}

\section{Kata Kunci:}

Rough Set,

Prediksi,

Ujian Kompetensi

\section{Keywords:}

Rough Sets,

Predictions,

Competency Tests

\begin{abstract}
ABSTRAK
Berdasarkan Peraturan Bersama antara Kemendikbud dan Kemenkes Tentang Ujian Kompetensi (UKom) Tahun 2013 No. 36/2013 \& No.I/Iv/Pb/2013, maka seluruh Perguruan Tinggi Kesehatan di Indonesia diwajibkan untuk melaksanakan UKom sebagai syarat untuk mendapatkan gelar bagi mahasiswa kesehatan dalam menyelesaikan studinya. Di Akademi Kebidanan Dehasen Bengkulu, Lulus UKom juga merupakan syarat utama untuk meraih gelar Amd.Keb. Oleh karena itu mahasiswa Kebidanan Dehasen Bengkulu diwajibkan mengikuti UKom. Sebelum melaksanakan UKom, dosen ataupun pihak kampus ingin memprediksi jumlah mahasiswa yang lolos dalam melaksanakan UKom. Selama ini pihak kampus mengalami kesulitan dalam memprediksi kelulusan mahasiswa dalam Ujian Kompetensi, sehingga menyebabkan tidak adanya tolak ukur dalam persiapan. Akhirnya hasil Ujian Kompetensi Kebidanan di Akbid Dehasen Bengkulu tidak sesuai dengan target yang diinginkan. Oleh sebab itu perlu sebuah Program yang dapat memprediksi kelulusan Ujian Kompetensi Kebidanan. Adapun Algoritma dalam memprediksi hasil kelulusan ini memakai Algoritma Rough Set. Penelitian ini dilakukan dengan mengamati beberapa variabel penelitian yang sering dipertimbangkan oleh perguruan tinggi kebidanan khususnya bagian akademik dalam memprediksi hasil UKom, yaitu 7 variabel nilai dalam ujian kompetensi kebidanan yaitu nilai dengan tipe soal tentang Ibu Hamil, Ibu Bersalin, Ibu Nifas, BBL, KB, Kespro, dan Patologi. Pada Algoritma Rough Set Variabel nilai hasil ujian kompetensi diakumulasikan menjadi sebuah variabel nilai dan diklasifikasikan pada kelas-kelas yaitu kelas jumlah muncul dan keterangan kelulusan. Hasil dari penelitian ini adalah berupa sebuah knowledge untuk memprediksi hasil ujian kompetensi kebidanaan dengan penerapan Algoritma Rough Set pada perangkat lunak Rosetta. Dari hasil penerapan Algoritma Rough Set untuk memprediksi hasil ujian kompetensi kebidanan, dapat disimpulkan bahwa Algoritma Rough Set sangat efektif dan efisien dalam menentukan hasil yang akurat sesuai dengan data aktual untuk sebuah acuan prediksi hasil kelulusan ujian kompetensi kebidanan di Akademi Kebidanan Dehasen Bengkulu. Setelah digunakan data kelulusan tahun sebelumnya pada Aplikasi Rosetta dengan Penerapan Algoritma Rough Set, didapatkan hasil Prediksi untuk kelulusan UKom tahun yang akan datang.
\end{abstract}


variables in the midwifery competency test, namely scores with types of questions about Pregnant Women, Maternal Mothers, Postpartum Mothers, BBL, Family Planning, Kespro, and Pathology. In the Rough Set Algorithm, the value of the competency test results is accumulated into a value variable and classified into classes, namely the number of appearances and graduation statements. The results of this study are in the form of knowledge to predict the results of midwifery competency exams with the application of the Rough Set Algorithm on the Rosetta software. From the results of the application of the Rough Set Algorithm to predict the results of the midwifery competency exam, it can be concluded that the Rough Set Algorithm is very effective and efficient in determining accurate results according to the actual data for a reference for predicting the results of passing the midwifery competency exam at the Dehasen Bengkulu Midwifery Academy. After using the previous year's graduation data on the Rosetta Application with the Application of the Rough Set Algorithm, the prediction results for UKom's graduation for the coming year were obtained.

This is an open access article under the CC BY-SAlicense.

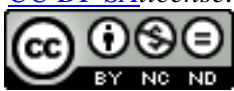

Penulis Korespondensi:

\section{PENDAHULUAN}

Di Akademi Kebidanan Dehasen Bengkulu, Lulus UKom juga merupakan syarat wajib untuk mendapatkan gelar Amd.Keb. Oleh karena itu mahasiswa Akademi Kebidanan Dehasen Bengkulu wajib mengikuti UKom. Sebelum melakukan Ujian Kompetensi, dosen ataupun pihak kampus tentu ingin tahu mengenai prediksi nilai dari Mahasiswa yang akan melaksanakan UKom. Selama ini pihak kampus mengalami kesulitan dalam memprediksi kelulusan mahasiswa dalam Ujian Kompetensi, sehingga menyebabkan tidak adanya tolak ukur dalam persiapan. Akhirnya hasil Ujian Kompetensi Kebidanan di Akbid Dehasen Bengkulu tidak sesuai dengan target yang diinginkan. Oleh sebab itu perlu sebuah Program yang dapat memprediksi kelulusan Ujian Kompetensi Kebidanan.

[1] Rough Set adalah pendekatan untuk mengekstrak pengetahuan dan hubungan antara data dan nilai-nilai data dalam beberapa tahun terakhir. Rough Set adalah sebuah set data direpresentasikan sebagai sebuah tabel, baris dalam tabel merepresentasikan objek dan kolomkolom merepresentasikan atribut dari objek-objek tersebut.Tabel tersebut disebut dengan information system. [2] Menurut A.J. Komorowski, Rough Set adalah sebuah Teknik Matematik yang dikembangkan oleh Pawlack pada tahun 1980. Rough Set menawarkan dua bentuk representasi data yaitu, Information System (IS) dan Decission System (DS). Penelitian dengan Rough Set dihasilkan oleh sejumlah software untuk mengolah data mining dan knowledge discovery database (KDD), Sofware Rosetta merupakan suatu percobaan ilmiah dimana prosesnya meliputi pengelompokan data yang terorganisir dengan tree structure serta menampilkan bagaimana input dan output data tersebut berhubungan satu sama lain. Software ini mendukung proses knowledge discovery database KDD secara keseluruhan mulai dari browsing dan processing data, menghitung reduct dan rule synthesis, validation dan analisis dari rule yang dihasilkan.

[3] Toleransi Rough Set Model bersantai persyaratan transitivitas hubungan kesetaraan, dan sering digunakan dalam pencarian informasi untuk menemukan kelompok istilah indeks dalam basis data teks besar. [4] Untuk melatih umpan-maju ANN classifier, kembali propagasi diaplikasikan sesuai dengan Duda dkk, dan 3-Sistem lapisan terpilih sebagai ANN BP standar. Lapisan input dari jaringan memiliki enam neuron yang sesuai untuk enam nilai fitur input.

[5] Data Mining atau sering disebut sebagai knowledge discovery in database (KDD) adalah kegiatan yang meliputi pengumpulan, pemakaian data historis untuk menemukan keteraturan, pola atau hubungan dalam data berukuran besar. Keluaran Data Mining ini bisa dipakai untuk 
membantu pengambilan keputusan di masa depan. Pengembangan KDD ini menyebabkan penggunaan pattern recognition semakin berkurang karena telah menjadi bagian Data Mining.

Dengan adanya Algoritma Rough Set maka pihak kampus bisa memprediksi nilai mahasiswa yang akan mengikuti UKom dari data nilai mahasiswa tahun sebelumnya. Algoritma Rough Set lebih cocok digunakan pada Aplikasi Rosetta dalam sebuah Program Prediksi, karena memiliki tingkat akurasi yang lebih tinggi dibandingkan dengan Algoritma yang lain.

\section{METODE PENELITIAN}

Dalam melakukan penelitian agar hasilnya bisa maksimal, tentunya harus mengikuti kaidah-kaidah (metode) yang telah ditetapkan. Metode penelitian yang akan diterapkan adalah metode penelitian ilmiah. Metodologi penelitian ini memuat tentang kerangka kerja penelitian yang akan dibahas di bawah ini.

Pada bab ini akan dibahas metodologi penelitian untuk mengidentifikasi data mining, analisa data dan pada akhirnya mencari kesimpulan di dalam memprediksi hasil Ujian Kompetensi mahasiswa Akademi Kebidanan Dehasen Bengkulu.

Metodologi penelitian yang digunakan dalam Penelitian ini adalah Metode Peneada urutan kerangka kerja yang harus diikuti, urutan kerangka kerja ini merupakan gambaran dari langkahlangkah yang harus dilalui agar penelitian ini bisa berjalan dengan baik. Kerangka kerja yang harus diikuti bisa dilihat pada gambar 2.1.

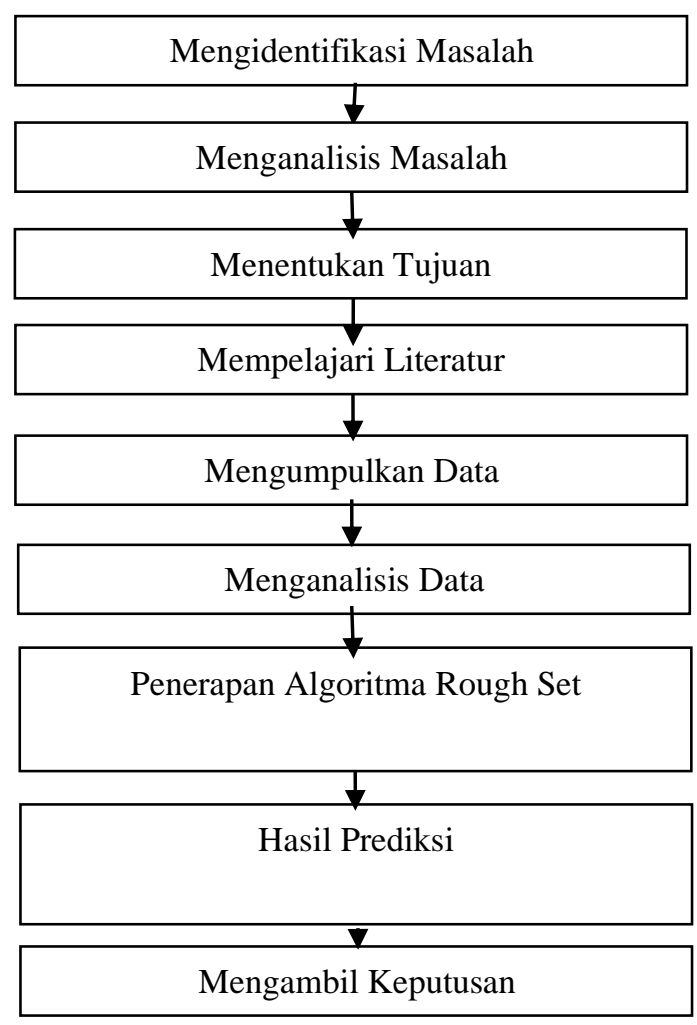

Gambar 1 Kerangka Kerja

\section{HASIL DAN ANALISIS}

Algoritma Rough Set memakai aplikasi Rosetta. Pada tahap pengujian ini akan dideskripsikan teknik menggunakan Aplikasi Rosetta dalam memprediksi hasil UKom Kebidanan di Akbid Dehasen Bengkulu.

\subsection{Hasil}


JSAI : Journal Scientific and Applied Informatics

Vol. 4, No. 2, Juni 2021, hal. 135 140

E-ISSN: 2614-3054; P-ISSN: 2614-3062, accredited by Kemenristekdikti, Sinta 5

DOI: 10.36085

Dalam Implementasi menggunakan Aplikasi Rosetta menghasilkan output berupa rule-rule, berikut hasil outputnya:

- If IH (50) AND Jumlah Muncul (2) then keputusan (lulus)

- If IH (48) AND Jumlah Muncul (2) then keputusan (lulus)

- If $\mathrm{IH}(60) A N D$ Jumlah Muncul (2) then keputusan (lulus)

- If IH (45) AND Jumlah Muncul (2) then keputusan (lulus)

- If IH (50) AND Jumlah Muncul (1) then keputusan (gagal)

- If IH (55) AND Jumlah Muncul (2) then keputusan (lulus)

- If IH (60) AND Jumlah Muncul (1) then keputusan (lulus)

- If Kespro (80) AND Jumlah Muncul (2) then keputusan (lulus)

- If Kespro (70) AND Jumlah Muncul (2) then keputusan (lulus)

- If Kespro (70) AND Jumlah Muncul (1) then keputusan (gagal)

- If Kespro (90) AND Jumlah Muncul (2) then keputusan (lulus)

- If Kespro (100) AND Jumlah Muncul (2) then keputusan (lulus)

- If Kespro (100) AND Jumlah Muncul (1) then keputusan (lulus)

- If IN (70) AND Jumlah Muncul (2) then keputusan (lulus)

- If IN (65) AND Jumlah Muncul (2) then keputusan (lulus)

- If IN (55) AND Jumlah Muncul (2) then keputusan (lulus)

- If IN (70) AND Jumlah Muncul (1) then keputusan (gagal) OR keputusan (lulus)

- If IN (80) AND Jumlah Muncul (2) then keputusan (lulus)

- If IN (80) AND Jumlah Muncul (1) then keputusan (lulus)

- If IN (67) AND Jumlah Muncul (2) then keputusan (lulus)

- If Keterangan Kelulusan (2) then Keputusan (lulus)

- If Keterangan Kelulusan (1) then Keputusan (gagal)

- If Jumlah Muncul (2) then Keputusan (lulus)

- If Jumlah Muncul (1) then Keputusan (gagal) or Keputusan (lulus)

Adapun tampilan hasil dari Rule-rule pada Aplikasi Rosseta adalah sebagai berikut:

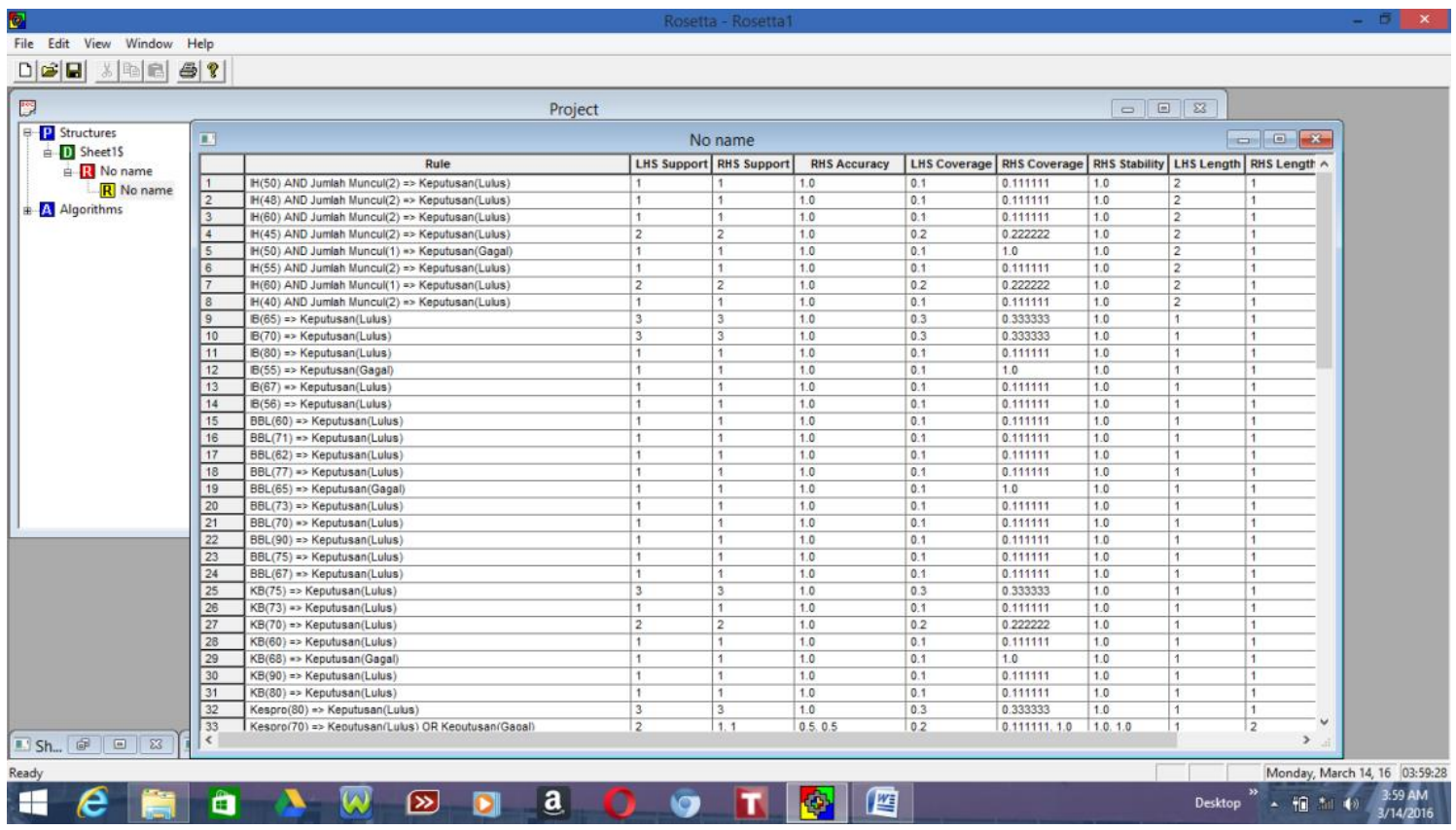

Gambar 2. Form Genarate Rule

\subsection{Analisis}

Pada proses pengujia pada software rosetta, dihasilkan rule-rule yang sesuai dengan variabel yang didapat dari hasil Ukom. Rule-rule tersebut yang nantinya akan menjadi alat bantu dalam memprediksi kelulusan hasil UKom. Rule-rule tersebut memperlihatkan kelulusan yang dikategorikan berupa "Lulus" atau "Gagal" 
JSAI : Journal Scientific and Applied Informatics

Vol. 4, No. 2, Juni 2021, hal. 135 140

E-ISSN: 2614-3054; P-ISSN: 2614-3062, accredited by Kemenristekdikti, Sinta 5

DOI: 10.36085

Rule-rule yang dihasilkan akan menuntun dosen-dosen untuk meningkatkan kualitas lulusan kebidanan di Akademi Kebidanan Dehasen Bengkulu. Berikut tabel data sampel dan hasil prediksi pada algoritma Rough Set dalam memprediksi hasil UKom kebidanan.

Adapun table hasil Prediksi pada Algoritma Rough Set adalah sebagai berikut:

Tabel 1. Hasil Prediksi pada Algoritma Rough Set

\begin{tabular}{|r|l|c|}
\hline \multicolumn{1}{|c|}{ No } & \multicolumn{1}{|c|}{ Hasil Rule Pada Rosetta } & Hasil \\
& & Prediksi \\
\hline 1 & If IH (50) AND Jumlah Muncul (2) then keputusan (lulus) & Benar \\
\hline 2 & If IH (48) AND Jumlah Muncul (2) then keputusan (lulus) & Benar \\
\hline 3 & If IH (60) AND Jumlah Muncul (2) then keputusan (lulus) & Benar \\
\hline 4 & If IH (45) AND Jumlah Muncul (2) then keputusan (lulus) & Benar \\
\hline 5 & If IH (50) AND Jumlah Muncul (1) then keputusan (gagal) & Benar \\
\hline 6 & If IH (55) AND Jumlah Muncul (2) then keputusan (lulus) & Benar \\
\hline 7 & If IH (60) AND Jumlah Muncul (1) then keputusan (lulus) & Benar \\
\hline 8 & If Kespro (80) AND Jumlah Muncul (2) then keputusan (lulus) & Benar \\
\hline 9 & If Kespro (70) AND Jumlah Muncul (2) then keputusan (lulus) & Benar \\
\hline 10 & If Kespro (70) AND Jumlah Muncul (1) then keputusan (gagal) & Benar \\
\hline 11 & If Kespro (90) AND Jumlah Muncul (2) then keputusan (lulus) & Benar \\
\hline 12 & If Kespro (100) AND Jumlah Muncul (2) then keputusan (lulus) & Benar \\
\hline 13 & If Kespro (100) AND Jumlah Muncul (1) then keputusan (lulus) & Benar \\
\hline 14 & If IN (70) AND Jumlah Muncul (2) then keputusan (lulus) & Benar \\
\hline 15 & If IN (65) AND Jumlah Muncul (2) then keputusan (lulus) & Benar \\
\hline 16 & IfIN (55) AND Jumlah Muncul (2) then keputusan (lulus) & Benar \\
\hline 17 & If IN (70) AND Jumlah Muncul (1) then keputusan (gagal) orkeputusan (lulus) & Benar \\
\hline 18 & If IN (80) AND Jumlah Muncul (2) then keputusan (lulus) & Benar \\
\hline 19 & If IN (80) AND Jumlah Muncul (1) then keputusan (lulus) & Benar \\
\hline 20 & If IN (67) AND Jumlah Muncul (2) then keputusan (lulus) & Benar \\
\hline 21 & If Keterangan Kelulusan (2) then keputusan (lulus) & Benar \\
\hline 22 & If Keterangan Kelulusan (1) then keputusan (gagal) & Benar \\
\hline 23 & If Jumlah Muncul (2) then keputusan (lulus) & Benar \\
\hline 24 & If Jumlah Muncul (1) then keputusan (gagal) or keputusan (lulus) & Benar \\
\hline & & \\
\hline
\end{tabular}

Dari semua rule yang dihasilkan pada aplikasi Rosetta dapat memprediksi dengan benar sesuai data sampel yang digunakan. Untuk menghitung tingkat akurasi pada algoritma Rough Set dalam memprediksi hasil UKom kebidanan dapat dilakukan dengan menghitung jumlah hasil prediksi benar dibagi dengan jumlah rule yang dihasilkan kemudian dikalikan dengan 100. Berikut ini perhitungan tingkat akurasi pada Algoritma Rough Set:

$$
\text { Akurasi }=\frac{24}{24} \times 100=100 \%
$$

Jadi tingkat akurasi pada Algoritma Rough Set dalam memprediksi hasil UKom kebidanan sebesar $100 \%$.

\section{KESIMPULAN}

Algoritma Rough Set dibuktikan dengan pengujian menggunakan aplikasi Rosetta didapatkan hasil berupa rule-rule/knowledge yang dapat digunakan untuk memprediksi lulus atau gagal dalam hasil ujian kompetensi kebidanan di Akademi Kebidanan Dehasen Bengkulu yang akan datang dengan lebih efektif dan efisien. Pada semua rule yang dihasilkan tersebut dapat memprediksi dengan benar sesuai data sampel yang digunakan dengan tingkat akurasi $100 \%$. 
JSAI : Journal Scientific and Applied Informatics

Vol. 4, No. 2, Juni 2021, hal. 135 140

E-ISSN: 2614-3054; P-ISSN: 2614-3062, accredited by Kemenristekdikti, Sinta 5

DOI: 10.36085

\section{UCAPAN TERIMA KASIH}

Terima Kasih Kepada Universitas Dehasen Bengkulu atas supportnya dalam Penelitian ini.

\section{REFERENSI}

[1] B. K. Tripathy, D. P. Acharjya, and V. Cynthya, "A F RAMEWORK FOR I NTELLIGENT M EDICAL D IAGNOSIS USING R OUGH S ET WITH F ORMAL,” vol. 2, no. 2, 2011.

[2] A. Putra, Z. A. Matondang, N. Sitompul, I. Pendahuluan, and A. Prediksi, "Implementasi Algoritma Rough Set Dalam Memprediksi Kecerdasan Anak," J. Pelita Inform., vol. 7, no. 2, pp. 149-156, 2018.

[3] Duntsch, et al. (2015). Rought Set Clustering. Technical Report\# CS-15-02. 1.

[4] Nukala, et al. (2014). An Efficient And Robust Fall Detection System Using Wireless Gait Analysis Sensor With Artificial Neural Network (ANN) And Support Vector Machine (SVM) Algorithms. 3. 31.

[5] Fadlina, (2014). Data Mining untuk Analisa Tingkat Kejahatan Jalanan dengan Algoritma Association RuleAlgoritma Apriori. INTI. Vol. 3. No. 1. 145. 